\title{
Determinantes da Rentabilidade das Instituições Financeiras no Brasil*
}

\section{Determinants of the Profitability of Financial Institutions in Brazil}

\author{
Fernando da Silva Vinhado** \\ José Angelo Divino***
}

\begin{abstract}
Resumo: O objetivo deste artigo é analisar os determinantes do desempenho recente do setor bancário brasileiro a partir da modelagem econométrica de duas medidas de rentabilidade, representadas pela Rentabilidade sobre o Patrimônio Líquido (ROE) e pela Rentabilidade sobre o Ativo (ROA). Entre as covariáveis consideradas, estão as características das instituições financeiras e do mercado bancário e as condições macroeconômicas do país. Para tanto, são realizadas estimações dinâmicas para dados organizados em painel com séries trimestrais de 71 bancos no período entre 2000 e 2008. Entre os principais achados estão a persistência dos níveis de rentabilidade, a identificação dos perfis das instituições mais rentáveis, o impacto negativo das estratégias de fusões e/ou aquisições e a relevância do cenário macroeconômico para a rentabilidade dos bancos. Além disso, a política monetária adotada no Brasil favorece aplicações das instituições financeiras em tesouraria, devido à rentabilidade obtida com a elevada taxa de juros e o reduzido nível de risco dos títulos públicos.
\end{abstract}

Palavras-chave: Instituições financeiras. Rentabilidade bancária. Painel dinâmico.

Abstract: The aim of this paper is to analyze the major determinants of the recent performance of the Brazilian banking sector by empirically modeling of two measures of profitability, represented by Return on Equity (ROE) and Return on Assets (ROA). Among the covariates are characteristics of financial institutions and of the banking sector and macroeconomic conditions of the country. The dynamic

* Os autores agradecem a dois pareceristas anônimos pelos valiosos comentários e sugestões que contribuíram para melhorar a qualidade do artigo. José A. Divino agradece ao CNPq pelo apoio financeiro. Os erros remanescentes são de responsabilidade exclusiva dos autores. As opiniões deste artigo não refletem as opiniões do Banco do Brasil ou de seus membros.

** $\quad$ Mestre em Economia de Empresas pela Universidade Católica de Brasília. Assessor Sênior na Diretoria de Controladoria do Banco do Brasil. Professor no Instituto Santana de Educação Superior (Faculdade LS).E-mail: fernando.vinhado@catolica.edu.br

** * Doutor em Economia pela Boston University. Professor do Programa de Pós-Graduação em Economia. Universidade Católica de Brasília.E-mail: jangelo@ucb.br 
estimations are conducted for a panel data with quarterly observations of 71 banks during the period from 2000 to 2008. Among the major results are the persistence of the profitability level, identification of the profile of the most profitable institutions, the negative impact of mergers or acquisitions and the relevance of the macroeconomic conditions for the bank profitability. Furthermore, the country monetary policy favors investments of financial institutions in treasure operations due to the high interest rate and low risk level of the government bonds.

Keywords: Financial institutions. Bank profitability. Dynamic panel data.

JEL Classification: C51; G21; L25.

\section{Introdução}

O setor bancário é tema recorrente na literatura financeira, pois envolve interesses de diversos agentes econômicos, tanto em um contexto macroeconômico quanto microeconômico. $\mathrm{O}$ aspecto macroeconômico deve-se à promoção de intermediação financeira entre agentes superavitários e deficitários e criação de mecanismos de pagamento para a sociedade, contribuindo para a dinâmica dos negócios, a liquidez e o desenvolvimento dos mercados. Já o lado microeconômico explica-se porque instituições bancárias podem ser vistas também como unidades produtivas, com fins lucrativos e interesses individuais específicos. Comportam-se, portanto, como firmas que buscam a otimização racional de lucros. Com tamanha amplitude e relevância, é imprescindível que as instituições que compõem o setor bancário apresentem níveis de produtividade e desempenho que garantam segurança à sociedade e retorno aos investidores.

$\mathrm{Na}$ economia brasileira, destacam-se alguns episódios marcantes, decorrentes do desempenho das instituições do setor bancário. Por exemplo, as falências de algumas instituições financeiras, como Banco Econômico, Banco Nacional, Banco Mercantil, Bamerindus, e outras; a edição de programas nacionais de auxílio e reestruturação de bancos (Proer, Proes, Proef); a reestruturação financeira dos bancos ocorrida após a estabilização da inflação alcançada com o advento do Plano Real em meados de 1994; e, mais recentemente, a ampliação da eficiência em intermediação financeira e geração de resultado, preservando os níveis de rentabilidade.

A estabilização da inflação ocorrida após 1994 definiu um momento de ruptura para o setor bancário brasileiro. Ao lograr êxito na estabilização dos preços, o Plano Real impôs um forte processo de ajuste aos bancos instalados no 
país à medida que acabou com os ganhos decorrentes de operações de floating. ${ }^{1}$ Isso levou a mudanças de estratégia operacional, com ganhos de inflação sendo substituídos por outras fontes de receita, redução de estrutura operacional e busca por flexibilidade e agilidade nos processos. Nesse cenário, para a adequada gestão ou supervisão bancária, torna-se essencial conhecer e quantificar as principais variáveis determinantes do desempenho econômico dos bancos.

O objetivo central deste artigo é analisar o desempenho recente do setor bancário brasileiro a partir da modelagem econométrica de duas medidas de rentabilidade amplamente usadas na literatura internacional de finanças, representadas pela Rentabilidade sobre o Patrimônio (ROE) e pela Rentabilidade sobre o Ativo (ROA). Para tanto, serão aplicadas técnicas de estimação de painel dinâmico via método de momentos generalizados (GMM), conforme proposto por Arellano e Bover (1995) e Blundell e Bond (1998). A ideia básica é identificar diferentes covariáveis associadas às especificidades das instituições e do setor financeiro, bem como às condições macroeconômicas do país. Enquanto na literatura internacional alguns estudos já aplicaram estimação de painel dinâmico para modelar rentabilidade bancária, no Brasil essa abordagem é nova.

Os resultados da estimação dinâmica sugerem persistência nos níveis de rentabilidade das instituições bancárias, mas com alta velocidade de ajustamento, indicando a possível existência de uma estrutura de mercado competitiva, ainda que o mercado bancário brasileiro seja dominado por poucas instituições. Os bancos privados e nacionais se mostraram mais rentáveis enquanto a estratégia de fusões e/ou aquisições tem desfavorecido a rentabilidade no período do negócio, com uma defasagem de aproximadamente um ano para influenciar positivamente a rentabilidade. $O$ grau de concentração do setor relaciona-se negativamente com a rentabilidade dos bancos, contrariando as evidências de outros países. Quanto à influência de políticas macroeconômicas sobre a rentabilidade dos bancos, observou-se que taxa básica de juros, inflação e crescimento do Produto Interno Bruto (PIB) afetam positivamente o desempenho econômico dos bancos. O confronto desses resultados com aqueles obtidos em estimações para outros países permitirá identificar semelhanças e diferenças entre o caso brasileiro e a evidência internacional.

O artigo está organizado conforme segue. Na seção 2 apresenta-se uma revisão de diversos estudos realizados para o Brasil e outros países. Na seção 3 são discutidas as equações estimadas e a modelagem econométrica utilizada. $\mathrm{Na}$ seção 4 é descrito o banco de dados e são apresentados e analisados os resultados obtidos. Por fim, na seção 5 apresentam-se as considerações finais.

$1 \quad$ Receitas líquidas de aplicação em ativos de curto prazo dos recursos não remunerados, tais como depósitos à vista, recursos em trânsito de terceiros, tributos a recolher e obrigações diversas não indexadas a índices de inflação. 


\section{Revisão da Literatura}

Diversos trabalhos na literatura financeira reportam estudos empíricos contemplando análises econométricas multivariadas dos fatores determinantes da rentabilidade das instituições financeiras.

Para países europeus, podem-se destacar os trabalhos de Goddard, Molyneux e Wilson (2004) e Athanasoglou, Delis e Staikouras (2006). O primeiro analisou a interação entre rentabilidade, medida pelo ROE, e crescimento de 583 instituições financeiras nos cinco maiores países da União Europeia ${ }^{2}$ no período de 1992 a 1998. Dentre os resultados, destacam-se o comportamento pró-cíclico do desempenho dos bancos e a correlação positiva da concentração do mercado, medida pelo índice de Herfindahl-Hirschman ( $\mathrm{IHH}$ ), com a rentabilidade bancária. Já o segundo estudo usou um painel não balanceado de bancos do Leste Europeu ${ }^{3}$ no período de 1998 a 2002 e também encontrou uma relação positiva de rentabilidade com inflação e com o IHH. Além disso, evidenciaram que bancos estrangeiros instalados naqueles países apresentavam maiores níveis de rentabilidade.

Outros países também têm demonstrado preocupação em estudar os determinantes da rentabilidade bancária. Athanasoglou, Brissimis e Delis (2008) analisaram o ROE e ROA para bancos comercias Gregos entre 1985 e 2001. Encontraram grau de persistência moderado nas medidas de rentabilidade e um comportamento de aversão ao risco por parte dos bancos. Tregenna (2009) analisou a rentabilidade de 644 instituições bancárias dos Estados Unidos no período de 1994 a 2005. Também encontrou persistência na rentabilidade e correlação positiva entre rentabilidade e o grau de concentração do setor. Flamini, McDonald e Schumacher (2009) investigaram 389 bancos de 41 países $^{4}$ da África Subsariana entre 1998 e 2006 . A rentabilidade se mostrou persistente e positivamente correlacionada com a inflação e o crescimento do PIB. Além disso, os bancos privados foram mais lucrativos. Já Garza-Garcia (2011) estudou o setor bancário no México com dados de 2001 a 2009 e identificou persistência, com baixa velocidade de ajuste, na rentabilidade dos bancos, e relação positiva dessa rentabilidade, medida por ROE e ROA, com a participação de mercado das instituições. Nesse estudo, os bancos mais capitalizados também se configuraram como mais rentáveis.

Para o mercado chinês, Sufian e Habibullah (2009) usaram 220 bancos e concluíram que os mesmos estão se rentabilizando a medida que diversificam seus

2 França, Alemanha, Itália, Espanha e Reino Unido.

3 Albânia, Bósnia, Bulgária, Croácia, Antiga República Iugoslava da Macedônia, Romênia e Sérvia e Montenegro.

4 Benin, Seychelles, Burundi, Lesoto, República Centro-Africana, Togo, Cabo Verde, Camarões, Mauritânia, Gana, República do Guiné Equatorial, Tanzânia, Maurícia, Senegal, Mali, Namíbia, Libéria, Costa do Marfin, Niger, África do Sul, Quênia, Botswana, Nigéria, Suazilândia, Etiópia, Angola, Gambia, Congo, Chade, Moçambique, Uganda, Madagascar, Serra Leoa, Malaui, Zâmbia, Guiné, Sudão, Zimbabue. 
portfólios e obtém maiores ganhos não associados a intermediação financeira. García-Herrero, Gavilá e Santabárbara (2009) enfatizaram o grau de intervenção política e a baixa rentabilidade do setor utilizando dados anuais de 87 bancos entre 1997 e 2004. Encontraram uma relação positiva de rentabilidade com o nível de capitalização, o volume de depósitos e inflação. Quanto à persistência da rentabilidade, consideraram como consequência do grau de intervenção do governo chinês por meio de barreiras impostas à competição ou capitalização e direcionamento dos modelos de negócios dos bancos.

No Brasil, essa literatura ainda é pouco explorada. Destaque-se o trabalho de Maffili, Bressan e Souza (2007), que estudaram a rentabilidade de vinte bancos de varejo $^{5}$ com dados semestrais entre 1999 e 2005. Por meio de estimadores convencionais em efeito fixo e aleatório, obtiveram uma relação positiva da rentabilidade com o spread bancário e com o nível de endividamento dos bancos. Os seus resultados também indicaram que as aplicações em títulos oferecem maior rentabilidade do que o crédito.

\section{Modelagem Econométrica}

\subsection{Modelo Empírico}

Diante dos objetivos propostos, serão estimadas equações para dois indicadores tradicionais de rentabilidade - Rentabilidade sobre o Patrimônio Líquido (ROE) e Rentabilidade sobre o Ativo (ROA). Essas são métricas amplamente utilizadas na literatura e no mercado, medindo lucratividade em relação aos investimentos dos sócios e da empresa, respectivamente.

Para os dois modelos propostos serão utilizadas covariáveis relativas às características individuais das instituições, do mercado financeiro e condições macroeconômicas do país. A escolha das variáveis explicativas baseou-se, fundamentalmente, em outros trabalhos da literatura internacional, com destaque para Athanasoglou, Delis e Staikouras (2006), Athanasoglou, Brissimis e Delis (2008) e García-Herrero, Gavilá e Santabárbara (2009), bem como na disponibilidade de informações do setor bancário brasileiro. Assim, na formulação geral dos modelos, as medidas de rentabilidade foram definidas como sendo explicadas por:

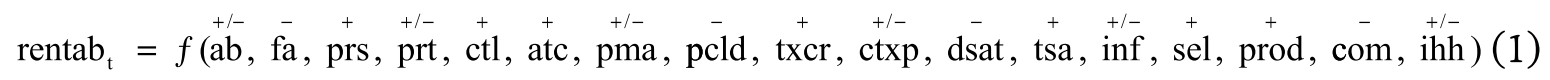

onde rentab é a rentabilidade medida por ROE e ROA, conforme descrito anteriormente. Acima de cada variável está o sinal esperado na regressão estimada. As

5 Banco do Brasil, Caixa Econômica Federal, Bradesco, Itau, Unibanco, Santander, ABN Amro, Safra, HSBC, Nossa Caixa, BankBoston, Banrisul, BNB, Basa, Banestes, Mercantil do Brasil, Rural, $\mathrm{BRB}$, Banese e Banpara. 
variáveis explicativas são nomeadas e discutidas a seguir. Para facilitar a explicação de cada variável e a discussão dos efeitos esperados, as séries foram divididas em dois grupos: (i) séries referentes às características individuais das instituições e (ii) séries referentes às condições macroeconômicas e do mercado. ${ }^{6}$

\subsubsection{Séries referentes às características individuais das instituições}

$a b=$ Negociante ou não de Ações na BMËFbovespa (dummy)

A decisão de negociar ou não ações em bolsa passa pela avaliação de algumas vantagens e desvantagens associadas à futura condição da empresa. Almeida Júnior (2007) destaca, como efeitos positivos na decisão de realizar um Initial Public Offering (IPO), a ampliação das fontes de captação de recursos e a redução de custos de carregamento de dívida. Porém, como efeitos negativos, há a elevação da exposição de informações financeiras e corporativas, a implantação de conselhos administrativos e fiscais e a consequente redução de autonomia na gestão, bem como o maior rigor na aplicação das regras contábeis. Oliveira, Schiozer e Saito (2009) enfatizam, também, o risco da abertura de capital ampliar o volume de operações ativas originadas em créditos de pior qualidade e/ou com menor spread e as mudanças significativas em termos de governança corporativa. Logo, tanto relações positivas quanto negativas podem ser esperadas entre a rentabilidade dos bancos e a negociação de ações na BMËFbovespa.

$f a=$ Adquirente ou não de outra Instituição por meio de Fusões e ou Aquisições (dummy)

Embora cortes de custos e economias de escala sejam dois aspectos que muitas vezes são considerados nas decisões de fusões e ou aquisições, de acordo com Araújo, Goldner, Faria e Brandão (2005), esses processos de fusões e/ou aquisições nem sempre estão associados a aumentos de retornos. Sugerem, ainda, que as instituições financeiras buscam diminuição de riscos de novos entrantes, dificultando o aumento da parcela de atuação dos atuais concorrentes. Carvalho (2007) destaca também que os próprios mercados compartilham dessa avaliação, já que, repetidamente, o valor de mercado das ações das instituições compradoras tem caído após anúncios de aquisições. Assim, o efeito esperado dessa variável sobre rentabilidade é negativo.

\section{prs $=$ Personalidade Jurídica Privada ou Pública (dummy)}

Tradicionalmente, os bancos públicos sempre foram vistos como menos rentáveis. Nesse sentido, Novaes (2007) destaca que se um banco estatal for tão eficiente quanto um privado, certamente não atenderá as razões pelas quais foi criado, especialmente no sentido de prover créditos para atividades consideradas

6 A fonte de cada variável, a forma de criação das variáveis dummies e as eventuais transformações a que as informações originais foram submetidas são discutidas na seção 4.1. 
prioritárias e não atendidas pelo setor privado em razão de falhas de mercado. A autora expõe, ainda, como motivos para o pior desempenho, a maximização de objetivos sociais, a ineficiência dos funcionários inadequadamente incentivados e os interesses políticos preservados. No mesmo sentido, Pinheiro (2007) destaca que os bancos privados são mais eficientes e lucrativos uma vez que seus proprietários são mais focados no lucro. Logo, monitoram melhor os negócios, promovendo inclusive melhores incentivos para gerentes e funcionários.

\section{prt = Organização Societária em Conglomerado ou Instituição Independente (dummy)}

Até 1988, as atividades dos bancos eram exercidas obrigatoriamente de forma segmentada, por entidades distintas que, dado controle acionário comum, configuravam conglomerados financeiros. A partir de então o Conselho Monetário Nacional autorizou a criação de bancos múltiplos permitindo a organização em diversos segmentos do mercado financeiro sob a mesma razão social. Navarro e Procianoy (1997) discutiram a questão e apontaram, como vantagem da transformação em banco múltiplo, a maior racionalização de procedimentos administrativos com redução dos custos de manutenção e, como desvantagem, a possibilidade de perdas de flexibilidade e a incapacidade de aproveitamento de incentivos tributários. Assim, são possíveis relações positivas ou negativas dessa variável com as medidas de rentabilidade.

$c t l=$ Origem do Controle Nacional ou Estrangeiro (dummy)

A queda de restrições legais impostas à entrada de instituições financeiras estrangeiras, aliada à estabilidade da inflação a partir do Plano Real e à globalização da economia aumentaram significativamente a quantidade de instituições bancárias com controle estrangeiro no Brasil. Segundo Guimarães (2002), a entrada dos bancos estrangeiros no Brasil foi acompanhada de um aumento na lucratividade dos bancos privados nacionais. Observa que, no Brasil, esses bancos têm desempenho melhor do que os bancos estrangeiros.

atc = Tamanho das Instituições em Ativos

A relação do tamanho das instituições com o nível de rentabilidade permite capturar evidências quanto a ganhos ou perdas provenientes de escala ou de escopo. ${ }^{7}$ Nessa linha, Faria, Paula e Marinho (2007) concluíram que os bancos são capazes de aumentar seus tamanhos sem que isso implique rendimentos decrescentes de escala. Isso, possivelmente, como resultado de altos investimentos em inovação tecnológica realizados nos últimos anos através da intensificação do uso

7 De acordo com Parkin (1995), uma economia de escala ocorre quando o aumento na produção de um bem ou serviço provoca um decréscimo no custo médio de produção, enquanto a economia de escopo ocorre quando o aumento nas linhas de produtos produzidos provoca redução no custo médio de produção. 
de tecnologias da informação, já que a indústria bancária é intensa em informação e distribuição de dados.

pma $=$ Participação no Mercado em Ativos

É recorrente, na estratégia das empresas de qualquer segmento, a busca por fatias de mercado. No entanto, a influência das parcelas de mercado conquistadas sobre o resultado é incerta e certamente pode depender muito do tamanho e esforço despendido na obtenção e do nível de concorrência do segmento. Nesse sentido, alguns trabalhos procuraram avaliar o impacto da participação de mercado na rentabilidade dos bancos, considerando inclusive a série como uma proxy de poder de mercado. Os resultados, divergentes entre estudos para bancos de outros países, indicam uma incerteza em relação aos efeitos da participação de mercado na rentabilidade dos bancos no Brasil.

pcld = Qualidade da Carteira de Crédito

De acordo com Athanasoglou, Brissimis e Delis (2008), a teoria sugere que o aumento na exposição a riscos de crédito está associado com a redução na rentabilidade das firmas. Logo, os bancos terão maior aversão a risco, buscando melhorar suas políticas de monitoramento e previsão de risco de crédito. Nessa direção, Molina (2004) destaca ainda que os bancos têm reduzido seus riscos nas operações de crédito através do aprimoramento dos procedimentos de análise de crédito.

\section{txcr = Participação das Aplicações em Tesouraria em Relação a Crédito}

As decisões de aplicação das instituições financeiras passam, basicamente, pela escolha entre o financiamento do setor privado, mediante operações de crédito, e do setor público, dado por títulos públicos para financiar dívidas do Estado. O primeiro é caracterizado por maior rentabilidade, maior risco e menor liquidez. Já o segundo possui menor rentabilidade, menor risco e maior liquidez. No entanto, no Brasil, segundo Silva e Oreiro (2007) os títulos públicos são a priori livres de riscos, rentáveis e de alta liquidez, rompendo com a tipologia ortodoxa de escolhas entre ativos rentáveis e de baixa liquidez (empréstimos e financiamentos) e ativos líquidos com baixa rentabilidade (ativos defensivos). Maffili, Bressan e Souza (2007) concluem também que aumentos nas aplicações em tesouraria (títulos) e diminuição nos volumes de crédito estão relacionados ao aumento da lucratividade dos bancos de varejo no Brasil.

ctxp = Participação dos Capitais de Terceiros em Relação aos Capitais Próprios A discussão sobre a escolha da estrutura ótima de capital iniciou-se, basicamente, com os trabalhos de Modigliani-Miller ${ }^{8}$ acerca do efeito do endividamento

$8 \quad$ Modigliani-Miller elaborou diversas proposições acerca do valor das empresas em função do nível de endividamento, considerando determinadas premissas e perspectivas: efeitos fiscais, dividendos, custo de falência e assimetria de informações. 
no resultado das empresas. A literatura a partir de então destaca, como efeito positivo do maior nível de endividamento da firma, os benefícios fiscais proporcionados pelas despesas financeiras e, como efeito negativo, os custos de agência ${ }^{9}$ e de risco de falência, ${ }^{10}$ conforme retratado por Ross, Westerfield e Jaffe (1995). Dessa forma, tanto relações positivas quanto negativas podem ser esperadas em relação à influência da estrutura de capitais dos bancos na rentabilidade.

$d s a t=$ Relação entre Despesas e o Total de Ativos

As mudanças ocorridas no setor bancário brasileiro a partir do controle da inflação e a consequente perda dos ganhos decorrentes de floating e do aumento da concorrência externa têm exigido das instituições financeiras a busca contínua pelo uso eficiente dos recursos mediante a gestão de despesas. Nesse sentido, embora seja indiscutível a relação negativa esperada com a rentabilidade, a grandeza da variável permite expressar ainda a relevância e contribuição do tema para a rentabilidade dos bancos.

\section{tsa = Relação entre Receitas de Serviços (tarifas) e o Total de Ativos}

A evolução das receitas de serviços no Brasil nos últimos anos, apresentada por Maffili, Bressan e Souza (2007) e também considerada como resultado das perdas de receitas com floating após o controle da inflação, certamente retrata a importância e a influência positiva da cobrança de tarifas no desempenho do setor. Isso justifica a inclusão da referida variável na modelagem proposta a fim de ratificar ou não tal mudança de estratégia, bem como capturar a grandeza dessa expansão e influência na formação da rentabilidade bancária.

\subsubsection{Séries referentes às condições macroeconômicas e do mercado}

\section{inf = Inflação medida pela variação do IPCA}

De acordo com Perry (1992), os efeitos da inflação na performance dos bancos dependem da capacidade dos mesmos em antecipar ou não seus efeitos na definição das taxas de juros e na precificação dos ativos. Paula e Pires (2007) enfatizam, ainda, que a taxa de inflação também representa uma medida de gerenciamento e estabilidade macroeconômica de um país, pois quanto maior (menor) a taxa de inflação, maior (menor) a instabilidade macroeconômica. Isso repercute, inclusive, sobre os riscos da intermediação financeira. Dessa forma, apesar da tendência de aumento do spread, a maior exposição a riscos, especialmente ao risco de crédito, tende a reduzir a rentabilidade dos bancos, tornando dúbio o efeito dessa variável sobre a rentabilidade.

9 Segundo Ross, Westernfield e Jaffe (1995), custos de agência decorrem de conflitos de interesses entre acionistas, credores e administradores, sendo os custos de agêncy aqueles necessários para resolver tais conflitos.

10 Risco de Falência ou Bankruptcy, segundo Matos (2001), é o conjunto de estados da natureza onde a firma é incapaz de pagar seus débitos. 
sel = Taxa Básica de Juros definida pelo COPOM como Selic meta

Segundo Paula e Pires (2007), a Selic desponta como a principal variável macroeconômica explicativa do spread bancário. Dada a existência de títulos indexados à Selic nas carteiras dos bancos, que é uma alternativa de aplicação rentável e líquida, o custo de oportunidade de emprestar por parte dos bancos tende a aumentar, passando a incorporar um elevado prêmio em seus empréstimos. Dessa forma, presume-se que elevações nessa taxa favoreçam a rentabilidade das instituições bancárias.

\section{prod $=$ PIB real desazonalizado}

Espera-se que o crescimento do produto da economia esteja associado a maiores volumes de negócios bancários, especialmente com o crédito conforme Sobreira (2007), influenciando positivamente os níveis de rentabilidade. Além disso, outros dois aspectos levantados por Silva, Oreiro e Paula (2007) também devem ser destacados. O primeiro indica que a elevação do PIB pode gerar um efeito negativo sobre a inadimplência bancária. O segundo levanta a possibilidade de geração de poder de mercado dos bancos em uma conjuntura de aumento da demanda por crédito. Assim, espera-se uma relação positiva entre produção e rentabilidade.

comp = Alíquota de Compulsório sobre os Depósitos à Vista

Segundo Leal (2007), o requerimento de reservas (compulsório) representa custo de oportunidade para a intermediação financeira. Porém, impacta o risco de liquidez das instituições, reduzindo o nível de liquidez dos bancos. A combinação desses aspectos indica a possibilidade de haver efeitos positivos e negativos, respectivamente, sobre a formação do spread bancário e níveis de rentabilidade. O aumento do spread reflete, porém, um simples repasse do maior custo, não devendo ser confundido com elevação de rentabilidade. Por fim, há também uma associação entre o aumento das exigências de compulsório a uma conjuntura de maior instabilidade macroeconômica, o que certamente impacta a capacidade de geração de negócios dos bancos.

ihh = Concentração do Setor medida pelo Índice de Herfindahl-Hirschaman

De acordo com a teoria econômica, maior concentração do setor poderia provocar coalizões entre os maiores bancos e exercício de poder de mercado que beneficiaria os lucros das empresas do setor. Nesse sentido, se a hipótese de poder de mercado estiver correta, então os índices de concentração teriam impacto sobre as taxas de empréstimo cobradas pelos bancos, resultando em maiores índices de rentabilidade. Cabe destacar, no entanto, que alguns autores como Nakane (2002), Nakane (2003), Molina (2004), Brandão, Oliveira, Goldner, e Gollner (2005), Carvalho (2007), Modenesi (2007) têm sinalizado que o setor bancário no Brasil vem se tornado, ao longo dos anos, cada vez mais competitivo 
na busca por participação de mercado pelas maiores instituições. Os líderes de mercado preocupam-se fortemente em manter ou ampliar suas fatias de mercado, até mesmo a expensas dos concorrentes, inclusive mediante crescimento por meio de alianças ou aquisições de outras instituições. Isso resulta em maiores níveis de concentração do setor. A disputa por maior participação no mercado pode tornar negativo o efeito da concentração bancária sobre os níveis de rentabilidade.

\subsection{Equação Estimada}

Rentabilidade no setor bancário, conforme sugere Berger et al. (2000), apresenta persistência ao longo do tempo. Para captar essa característica, foi adotada uma especificação dinâmica para o modelo de dados em painel. A forma geral das equações estimadas para cada medida de rentabilidade pode ser escrita como:

$\lg$ rentab $_{\mathrm{i}, \mathrm{t}}=\mathrm{c}+\delta_{1} \lg$ rentab $_{\mathrm{i}, \mathrm{t}-\mathrm{t}}+\delta_{2} a b_{\mathrm{i}, \mathrm{t}}+\delta_{3} f_{\mathrm{i}, \mathrm{t}}+\delta_{4} p r_{\mathrm{i}, \mathrm{t}}+\delta_{5} p \mathrm{pt}_{\mathrm{i}, \mathrm{t}}+\delta_{6} c t_{\mathrm{i}, \mathrm{t}}+\delta_{7} \lg a t c_{\mathrm{i}, \mathrm{t}}+\delta_{8} \lg a t c_{\mathrm{i}, \mathrm{t}}{ }^{2}+$

$+\delta_{9} \lg p m a_{\mathrm{i}, \mathrm{t}}+\delta_{10} \lg p c l d_{\mathrm{i}, \mathrm{t}}+\delta_{11} \lg \operatorname{txcr}_{\mathrm{i}, \mathrm{t}}+\delta_{12} \lg \operatorname{ctxp} \mathrm{p}_{\mathrm{i}, \mathrm{t}}+\delta_{13} \lg d s a_{\mathrm{i}, \mathrm{t}}+\delta_{14} \lg t s a_{\mathrm{i}, \mathrm{t}}+\delta_{15}$ inf $_{\mathrm{t}}+\delta_{16}$ sel $_{\mathrm{t}}+$

$+\delta_{17} \operatorname{prod}_{\mathrm{t}}+\delta_{18} \operatorname{comp}_{\mathrm{t}}+\delta_{19} i h h_{\mathrm{t}}+\varepsilon_{\mathrm{i}, \mathrm{t}}$

onde as definições das variáveis seguem aquelas apresentadas na seção anterior, lg antes do nome da variável indica que a mesma foi transformada em logaritmo base 10, c é o termo constante, $\varepsilon_{\mathrm{i}, \mathrm{t}}$ é o termo de erro composto $\varepsilon_{\mathrm{i}, \mathrm{t}}=\eta_{i}+u_{i, t} \mathrm{e}$ $\delta_{\mathrm{j}}$, com $\mathrm{j}=1,2, \ldots, 19$, são os coeficientes a serem estimados pela regressão.

A presença da variável dependente defasada na equação (2) inviabiliza a aplicação dos estimadores convencionais de efeitos fixos ou aleatórios por causa da correlação entre aquela variável e o termo de erro composto. O procedimento usado para estimar esse painel dinâmico é baseado em Arellano e Bover (1995) e Blundell e Bond (1998), denominado sistema GMM (ou GMM-SYS), que aprimoraram consideravelmente o estimador original de Arellano e Bond (1991). A ideia básica desse estimador original é calcular a primeira diferença da equação dinâmica para eliminar a heterogeneidade indivíduo-específico, fonte da correlação com a variável dependente defasada, e usar defasagens das variáveis em nível como instrumentos para as variáveis endógenas e predeterminadas em primeira diferença.

Porém, por causa da fraca correlação entre defasagens em nível e variáveis em primeira diferença, pode-se incorrer no problema de instrumentos fracos, especialmente quando as séries envolvidas na estimação apresentam elevada persistência. Nesse caso, Blundell e Bond (1998) mostram que o resultante estimador GMM em primeira diferença apresenta propriedades de pequena amostra indesejáveis, incluindo viés e imprecisão. Arellano e Bover (1995) e Blundell e Bond (1998) propuseram um estimador GMM aumentado, incluindo a equação original em nível em um sistema GMM. Assim, podem-se usar defasagens das variáveis em primeira diferença como instrumentos para a equação em nível, obtendo-se um 
conjunto adicional que condições de momento que melhora as propriedades de pequena amostra do estimador resultante.

Combinando-se ambos os conjuntos de condições de momento amostral tem-se o estimador GMM-SYS, o qual reduz consideravelmente o viés de pequena amostra do estimador original de Arellano e Bond (1991). Por construção, o modelo GMM-SYS é sobreidentificado para T $>3$, dado que usa todas as defasagens disponíveis como potenciais condições de momento. A especificação do modelo deve ser testada usando o teste de Hansen (1982).

\section{Resultados}

\subsection{Descrição dos Dados}

Foram utilizados dados trimestrais relativos a 71 instituições financeiras ${ }^{11}$ atuantes no Brasil e indicadores macroeconômicos durante o período de 2000:T1 a 2008:T2, totalizando 34 trimestres. Os dados foram organizados em painel balanceado, referente a todas as instituições financeiras que possuíam informações completas para o período estudado. A escolha do período de estudo se pautou na existência de instabilidades no setor, tanto antes de 2000, devida adaptação e crise bancária no pós-Plano Real, bem como no período pós-2008, em razão dos impactos da crise americana no setor. A seguir, são descritas as variáveis e suas respectivas fontes. ${ }^{12}$

$R O E=$ rentabilidade sobre o patrimônio líquido: é o quociente entre o lucro líquido obtido no trimestre e o patrimônio líquido apurado no final do mesmo período (BANCO CENTRAL DO BRASIL).

$R O A=$ rentabilidade sobre o ativo: é o quociente entre o lucro líquido obtido no trimestre e o total de ativos observado no final do mesmo período (BANCO CENTRAL DO BRASIL).

$a b=$ negociante ou não de ações na BMËFBovespa: variável dummy que assume valor 1 quando o banco negocia ações na BMËFBovespa no trimestre

11 Abc-Brasil, Abn Amro, Alfa, Bancap, Bancnacion, Bancoob, Banese, Banestes, Banpara, Banrisul, Bansicredi, Barclays, Basa, Banco do Brasil, BBM, Bco. John Deere, Bco. Uruguai, Bepi, Besc, Bgn, Bic, Bmg, Bnb Bnp Paribas, Bonsucesso, Bradesco, Brascan, Brb, Bva, Cédula, Cef, Citibank, Credibel, Cruzeiro do Sul, Daycoval, Dbb Bm, Deutsche, Fibra, Ficsa, Ge Capital, Gerdau, Guanabara, Hsbc, Industrial do Brasil, Ing, Intercap, Itau, La Provincia, La República, Luso Brasileiro, Matone, Mercantil do Brasil, Modal, Nossa Caixa, Ubs Pactual, Pine, Prosper, Rabobank, Renner, Ribeirão Preto, Rural, Safra, Santander, Schahin, Societe Generale, Sofisa, SS(Panamericano), Triângulo, Unibanco, Votorantin e Vr.

12 A estimação do GMM-SYS requer que as variáveis envolvidas sejam estacionárias. As séries foram testadas para a presença de raiz unitária e os resultados indicaram que o painel é estacionário. Os resultados não foram inseridos no artigo para economizar espaço, mas estão disponíveis mediante solicitação. 
e valor 0 em caso contrário (BOLSA DE VALORES, MERCADORIAS E FUTURO - BMEFBovespa).

$f a=$ adquirente ou não de outra instituição por meio de fusões e ou aquisições: variável dummy que assume valor 1 quando o banco adquire participação de outra instituição financeira no período e valor 0 caso não adquira (RISKBANK SISTEMA DE CLASSIFICAÇÃO DE RISCO BANCÁRIO).

prs = personalidade jurídica privada ou pública: variável dummy que assume valor 1 em caso de banco privado e 0 em caso de banco estatal (BANCO CENTRAL DO BRASIL).

prt = organização societária em conglomerado ou instituição independente: variável dummy que assume valor 1 para instituição organizada em forma de conglomerado e valor 0 no caso de instituição independente (BANCO CENTRAL DO BRASIL).

$c t l$ = origem do controle nacional ou estrangeiro: variável dummy que diferencia as instituições em função da nacionalidade, sendo 1 quando nacional e 0 quando estrangeira (BANCO CENTRAL DO BRASIL).

atc = tamanho das instituições em ativos: total de ativos no final de cada trimestre corrigido monetariamente por índice de inflação (IPCA), com período base em junho de 2008. (BANCO CENTRAL DO BRASIL).

pma = participação no mercado em ativos: participação de mercado em volume de ativos em relação ao total observado no Sistema Financeiro Nacional. (BANCO CENTRAL DO BRASIL).

pcld = qualidade da carteira de crédito: risco de crédito, considerando as provisões constituídas para créditos em liquidação duvidosa dividido pelo saldo das operações de crédito e arrendamento mercantil (BANCO CENTRAL DO BRASIL).

txcr = participação das aplicações em tesouraria em relação a crédito: quociente da divisão das aplicações em títulos, valores mobiliários e aplicações interfinanceiras pelas aplicações em operações de crédito e arrendamento mercantil (BANCO CENTRAL DO BRASIL).

ctxp = participação dos capitais de terceiros em relação aos capitais próprios: quociente da divisão das fontes de terceiros (depósitos, captações no mercado aberto, aceites e emissões de títulos, relações interfinanceiras, relações interdependências, empréstimos e repasses, instrumentos financeiros derivativos e outras obrigações) pelo patrimônio líquido (BANCO CENTRAL DO BRASIL).

$d s a t$ = relação entre despesas e o total de ativos: quociente da divisão das despesas administrativas, inclusive pessoal e tributárias, pelo total de ativos (BANCO CENTRAL DO BRASIL). 
tsa = relação entre receitas de serviços (tarifas) e o total de ativos: quociente da divisão das receitas com prestação de serviços pelo total de ativos (BANCO CENTRAL DO BRASIL).

inf = inflação medida pela variação do IPCA: variação trimestral do índice IPCA. (INSTITUTO BRASILEIRO DE GEOGRAFIA E ESTATÍSTICA).

sel = taxa básica de juros definida pelo Copom como Selic meta: taxas de juros capitalizadas trimestralmente (BANCO CENTRAL DO BRASIL).

prod $=$ variação trimestral no PIB real desazonalizado. (INSTITUTO BRASILEIRO DE GEOGRAFIA E ESTATÍSTICA).

com = alíquota de compulsório sobre os depósitos à vista: requerimento compulsório de reservas feito pelo Banco Central sobre os depósitos à vista (BANCO CENTRAL DO BRASIL).

ihh = concentração do setor medida pelo Índice de Herfindahl-Hirschman: índice usado para medir a concentração bancária, considerando o volume total de ativos (BANCO CENTRAL DO BRASIL).

\subsection{Estimação e Análise}

Os resultados das estimações para as medidas de rentabilidade ROE e ROA, definidas anteriormente, são reportados na Tabela 1. É interessante observar, inicialmente, a qualidade dos modelos estimados indicada pelos testes de autocorrelação de segunda ordem e sobreidentificação das condições de momento. O teste de Arellano e Bond (1991) revela, conforme esperado, presença de autocorrelação de primeira ordem nos resíduos do modelo e ausência de autocorrelação serial de segunda ordem. O teste de Hansen-Sargan, por sua vez, revela que a hipótese nula de sobreidentificação não pode ser rejeitada em nenhum dos modelos estimados, validando o conjunto de instrumentos utilizados e confirmando a robustez das estimações. A interpretação dos coeficientes estimados é apresentada em sequência.

\subsubsection{Características específicas das instituições financeiras}

As variáveis dependentes defasadas, nos dois modelos, indicam baixa persistência dos ganhos das instituições financeiras, confirmando a hipótese de Berger et al. (2000). Segundo Athanasoglou, Brissimis e Delis (2008), ${ }^{13}$ os valores dos coeficientes estimados, $R O E_{t-1}=0,10$ e $R O A_{t-1}=0,15$, sugerem que a rentabilidade dos bancos brasileiros possui baixa persistência e elevada velocidade de ajustamento, caracterizando a existência de uma estrutura competitiva no mercado bancário brasileiro. Embora esse mercado seja reconhecidamente dominado por poucas

13 Segundo os autores, um coeficiente entre 0 e 1 indica que a rentabilidade persiste, sendo o valor próximo de 0 um indicativo de que a indústria é bastante competitiva, e um valor próximo de 1 uma estrutura pouco competitiva. 
instituições, conforme já destacado, a competição ocorre para ampliar a participação individual no mercado. Lucinda (2010) também encontra evidências favoráveis à existência de algum grau de competitividade no setor bancário do país.

A série $a b$ (Negociante ou não de Ações na BMËFBovespa) apresentou coeficientes negativos nas duas regressões, indicando que as instituições com ações na BMEFFBovespa apresentam menor rentabilidade. Esses resultados sugerem, conforme discutido na seção anterior, que as exigências impostas às sociedades com ações em bolsa, como exposição de informações financeiras e corporativas, implantação de conselhos, rigor na aplicação das regras contábeis e outras, podem reduzir a rentabilidade dos bancos no Brasil. Cabe salientar ainda que, no Brasil, a quase totalidade das instituições públicas negocia ações em bolsa de valores, o que também pode ajudar a entender o resultado encontrado.

Tabela 1 - Resultados dos modelos estimados

\begin{tabular}{lcc}
\hline & $\begin{array}{c}\text { ROE }- \text { Rent. s/ } \\
\text { Patrimônio }\end{array}$ & ROA - Rent. s/ Ativo \\
\hline constante (coeficiente linear) & $-0,246$ & $-0,034^{* *}$ \\
& $(0,163)$ & $(0,015)$ \\
variável dependente em t-1 & $0,103^{* * *}$ & $0,152^{* * *}$ \\
& $(0,004)$ & $(0,004)$ \\
ab - negociante ou não de ações na & $-0,042^{* * *}$ & $-0,004^{* * *}$ \\
BMFEBBovespa (dummy) & $(0,005)$ & $(0,001)$ \\
fa - adquirinte ou não de outra & $-0,003^{* *}$ & 0,000 \\
instituição por meio de fusões e ou & $(0,001)$ & $(0,000)$ \\
aquisições (dummy) & & \\
prs - personalidade jurídica privada & $0,073^{* * *}$ & $0,015^{* * *}$ \\
ou pública (dummy) & $(0,016)$ & $(0,002)$ \\
prt - organização societária em & $-0,011^{* * *}$ & $-0,007$ \\
conglomerado ou independente & $(0,002)$ & $(0,001)$ \\
(dummy) & & \\
ctl - origem do controle nacional ou & $0,090^{* * *}$ & $0,002^{* * *}$ \\
estrangeiro (dummy) & $(0,006)$ & $(0,001)$ \\
atc - tamanho das instituições em & $0,120^{* * *}$ & $0,022^{* * *}$ \\
ativos & $(0,054)$ & $(0,005)$ \\
atc2 - tamanho das instituições em & $-0,004$ & $-0,001^{* * *}$ \\
ativos (quadrática) & $(0,004)$ & $(0,000)$ \\
pma - participação no mercado em & $-0,952$ & $-0,006$ \\
ativos & $(0,679)$ & $(0,157)$ \\
pcld - qualidade da carteira de & $-0,236^{* * *}$ & $-0,081^{* * *}$ \\
crédito & $(0,014)$ & $(0,002)$ \\
txcr - participação das aplicações & $0,027^{* * *}$ & $0,001^{* * *}$ \\
em tesouraria em relação a crédito & $(0,003)$ & $(0,000)$ \\
\hline
\end{tabular}

continua... 


\begin{tabular}{lcc}
\hline ctxp - participação dos capitais de & $-0,324^{* * *}$ & $-0,032^{* * *}$ \\
terceiros em relação aos capitais & $(0,013)$ & $(0,002)$ \\
próprios & & \\
dsat - relação entre despesas e o & $-2,876^{* * *}$ & $-0,297^{* * *}$ \\
total de ativos & $(0,220)$ & $(0,015)$ \\
tsa - relação entre receitas de servi- & $4,375^{* * *}$ & $0,495^{* * *}$ \\
ços (tarifas) e o total de ativos & $(0,815)$ & $(0,024)$ \\
inf - inflamação medida pela varia- & $0,498^{* * *}$ & $0,196^{* * *}$ \\
ção do IPCA & $(0,204)$ & $(0,010)$ \\
sel - taxa básica de juros definida & $0,553^{* * *}$ & $0,108^{* * *}$ \\
pelo COPOM como Sellic meta & $(0,126)$ & $(0,009)$ \\
prod - PIB real desazonalizado & $0,144^{* * *}$ & $0,044^{* * *}$ \\
& $(0,044)$ & $(0,005)$ \\
comp - alíquota de compulsório & $-0,036^{* * *}$ & $-0,007^{* * *}$ \\
sobre os depósitos à vista & $(0,010)$ & $(0,001)$ \\
ihh - Concentração do Setor medida & 0,222 & $-0,118^{* * *}$ \\
pelo Índice de Herfindahl-Hirsch- & $(0,179)$ & $(0,013)$ \\
man & & 71 \\
\hline Qt. Indivíduos & 71 & 33 \\
Qt. Períodos & 33 & 2.343 \\
Nr. Observações & 2.343 & 112 \\
Qt. Instrumentos & 112 & $x^{2}(19)=67.061$ \\
Wald-Test & $x^{2}(19)=32.548$ & $p-v a l=0,000$ \\
& $p-v a l=0,000$ & $-3,273 p-v a l=0,001$ \\
\hline AR(1) & $-3,724 p-v a l=0,000$ & $0,090 p-v a l=0,927$ \\
AR(2) & $0,401 p-v a l=0,687$ & $x^{2}(92)=56,017$ \\
\hline Sargan & $x^{2}(92)=54,024$ & 0,998 \\
\hline Fonte: Elaboraçäo prôpra. &
\end{tabular}

Fonte: Elaboração própria.

Nota: $* *, * * e^{*}$ denotam significância estatistica dos coeficientes a 1\%, 5\% e $10 \%$, respectivamente.

A fim de controlar esse efeito cruzado, incluiu-se uma variável dummy de interação, pxa, envolvendo o produto das variáveis dummies ab (ações em bolsa) e prs (personalidade jurídica). O coeficiente estimado revelou que os bancos privados sem ações na BMËFBovespa são mais rentáveis do que aqueles com ações. Esses últimos, por sua vez, são mais rentáveis do que os públicos com ações, os quais são mais rentáveis do que os públicos sem ações negociadas na BMËFbovespa (vide Anexo A).

A aquisição de outra instituição financeira pode levar a perda de rentabilidade para o adquirente. $\mathrm{O}$ coeficiente negativo e estatisticamente significante de 
fa para a equação de $R O E$ indica que as fusões e/ou aquisições efetuadas no setor bancário brasileiro têm prejudicado, no período do negócio, a rentabilidade dos adquirentes. Complementarmente, as equações foram reestimadas com $f a$ em até quatro defasagens a fim de se encontrar uma inversão de sinal para essa variável. O resultado para o ROE apontou relação positiva e estatisticamente significante na quarta defasagem, sugerindo o prazo de um ano para que as fusões e/ou aquisições passassem a favorecer a rentabilidade (vide Anexo A).

Quanto à personalidade jurídica público ou privada, as estimações apresentaram coeficientes positivos e estatisticamente significantes, ratificando a hipótese de que as instituições privadas apresentam maiores níveis de rentabilidade sobre o patrimônio líquido e sobre os ativos do que as públicas.

Uma maior quantidade de subsidiárias abertas dentro do mesmo grupo pode prejudicar a rentabilidade das instituições, caracterizando a possível existência de maiores custos de manutenção ou de agência. Esse resultado se deve aos coeficientes negativos e estatisticamente significantes de prt em ambos os modelos estimados.

A origem do controle das instituições financeiras, se nacional ou estrangeira, corrobora as considerações de Guimarães (2002), segundo as quais os bancos estrangeiros têm sido menos rentáveis do que os de capital nacional. Isso se deve, provavelmente, à forte reação dos bancos nacionais à entrada dos bancos estrangeiros e às maiores margens líquidas de juros praticadas pelos bancos privados nacionais.

Já o tamanho das instituições em ativos (atc) se relaciona positivamente com ambas as medidas de rentabilidade, ROE e ROA, sugerindo que os grandes bancos têm apresentado maiores níveis de rentabilidade. Esse resultado permite identificar a existência de ganhos de escala ou escopo no setor bancário brasileiro. Visando encontrar um tamanho médio ótimo para os bancos, foi inserida a série atc na forma quadrática. Contudo, essa se mostrou significante apenas no modelo estimado para ROA e com um coeficiente estimado muito baixo. Esse resultado não permite concluir sobre a existência de uma forma quadrática para essa variável na regressão.

A qualidade da carteira de crédito apresentou coeficiente estimado negativo e significante nas duas equações estimadas, revelando que maior exposição a risco de crédito prejudica a rentabilidade dos bancos. Esse resultado ratifica a evidência obtida por Athanasoglou, Brissimis e Delis (2008).

A série $t x c r$, referente à participação das aplicações em tesouraria em relação ao crédito, mostra que a razão entre o quanto o banco aplicou em títulos para cada unidade aplicada em crédito afetou positivamente as medidas de rentabilidade. Assim, instituições com maior participação de aplicações em tesouraria obtêm maiores rentabilidades por causa da elevada taxa de juro oferecida pelos títulos 
públicos brasileiros. Resultado semelhante foi encontrado por Maffili, Bressan e Souza (2007), que concluíram que aumentos nas aplicações em tesouraria e diminuição nos volumes de crédito estão relacionados ao aumento da lucratividade de bancos de varejo no Brasil.

A relação entre os capitais de terceiros e próprios, dada pela variável ctxp, que evidencia o quanto o banco possui de capital de terceiros (debt) para cada unidade de capital próprio (equity) e procura capturar o efeito do endividamento no resultado das empresas, indicou relação negativa entre o grau de endividamento e a rentabilidade dos bancos. Tal resultado mostra-se alinhado com as hipóteses de custo de risco de bankruptcy e custo de agência. Bancos mais endividados representam maiores níveis de risco para seus credores, que passam a exigir taxas mais elevadas, bem como a incidência de custos decorrentes de conflito de interesses entre credores e acionistas.

A ineficiência, medida pela representatividade das despesas administrativas em relação ao tamanho das instituições, mostrou-se, conforme esperado, negativamente relacionada com a rentabilidade dos bancos. Por outro lado, quanto à prestação de serviços e consequente cobrança de tarifas, foi encontrada relação positiva com a rentabilidade. Diante da grandeza dos coeficientes estimados para as variáveis dsat e tsa, pode-se destacar a relevância da gestão de despesas e cobrança de tarifas na determinação da rentabilidade das instituições financeiras.

\subsubsection{Variáveis macroeconômicas agregadas}

O comportamento das variáveis macroeconômicas pode ter um impacto importante na explicação da rentabilidade do setor bancário do país. A primeira série considerada na análise foi a taxa de inflação. Os coeficientes positivos e estatisticamente significantes em ambos os modelos estimados, em conformidade com Perry (1992), sugerem que os bancos no Brasil conseguem prever e ajustar as taxas de juros em seus principais negócios de forma a antecipar os efeitos da inflação. Essa evidência, porém, contradiz a posição de Paula e Pires (2007) acerca da inflação como medida de gerenciamento e estabilidade macroeconômica de um país, que está associada à elevação dos riscos da intermediação financeira. A capacidade dos bancos de prever mudanças na inflação e ajustar as taxas de retorno de suas operações, conforme sugerido por Perry (1992), advém do longo período que tiveram que conviver com elevadas taxas de inflação e instabilidade econômica no país.

Os resultados obtidos para a variável taxa de juros, com coeficientes positivos e significantes para ROE e ROA, permitem ratificar a influência da política monetária, via taxa Selic, sobre a rentabilidade dos bancos. Isso se dá por meio de ganhos (perdas) nas carteiras de títulos e de crédito em contextos de elevação (redução) dos juros, dada existência de títulos indexados à Selic, bem como por se tratar de 
um custo de oportunidade para as operações de crédito, conforme sugerem Paula e Pires (2007). A grandeza dos coeficientes estimados para essa variável na Tabela 1 confirma a sua relevância para a formação da rentabilidade bancária.

O crescimento econômico do país, medido pela variação real do produto interno bruto, mostra um efeito positivo e estatisticamente significante para ambas as medidas de rentabilidade aqui adotadas. Assim, a rentabilidade dos bancos é pró-cíclica, possivelmente em razão do maior volume de negócios dos bancos em períodos de maior expansão econômica, especialmente com crédito, conforme apontado por Sobreira (2007).

A alíquota de compulsório sobre os depósitos à vista atua para reduzir a rentabilidade do setor financeiro. Os coeficientes negativos sugerem que quanto maior a alíquota dos depósitos compulsórios, menor a rentabilidade dos bancos. Esse resultado aponta para as considerações de Leal (2007), que considera o requerimento de compulsório como um custo de oportunidade para a atividade bancária, o que impacta negativamente a capacidade de geração de negócios e a rentabilidade dos bancos.

Por fim, vale analisar o impacto da concentração do setor, medido pelo índice de Herfindahl-Hirschman (IHH), sobre rentabilidade. Enquanto a estimação para o ROE não foi estatisticamente significante, o resultado para o ROA indicou relação negativa com a concentração do setor, afastando a possibilidade de existência de coalizões e exercício de poder de mercado pelas instituições financeiras no Brasil. Nesse sentido, cabe enfatizar também que, embora o IHH tenha apresentado tendência crescente nos últimos anos, indicando que o setor está cada vez mais concentrado, o IHH ficou situado abaixo de 0,10 durante todo o período, com valor médio igual a 0,086. Segundo Parkin (1995), isso indica que o mercado bancário ainda é competitivo na economia brasileira. ${ }^{14}$ Rocha (2001) também destaca que o IHH no Brasil não é elevado, sendo menor do que os valores encontrados para outros países da América Latina.

Outro aspecto que reforça os resultados anteriores é a relação inversa observada entre o grau de concentração e os spreads praticados no Brasil. ${ }^{15}$ Enquanto a concentração bancária apresentou tendência crescente no período estudado, o spread bancário mostrou tendência decrescente.

Estimações adicionais foram realizadas substituindo-se o IHH pela razão de concentração, CR10. Os resultados, reportados no Anexo A, ratificam a evidência anterior entre rentabilidade e IHH. O coeficiente negativo e estatisticamente significante de CR10 na regressão de ROA confirma a relação inversa entre rentabilidade e concentração bancária.

14 De acordo com Parkin (1995), quando o IHH está situado abaixo de 0,10 o mercado é considerado competitivo, entre 0,10 e 0,18 é moderadamente concentrado e acima de 0,18 é concentrado.

15 Spread geral em operações com pessoa física e jurídica divulgado mensalmente pelo Banco Central do Brasil. 


\section{Considerações Finais}

O objetivo deste artigo foi modelar os determinantes da rentabilidade recente do setor bancário brasileiro. Como medidas de rentabilidade, foram usadas a Rentabilidade sobre o Patrimônio (ROE) e Rentabilidade sobre o Ativo (ROA). Os dados foram organizados em painel para 71 bancos no período de 2000/1 a 2008/2, totalizando 34 trimestres. Por conta da estrutura dinâmica da equação estimada, foram aplicadas técnicas de estimação de painel dinâmico via método de momentos generalizados (GMM), conforme proposto por Arellano e Bover (1995) e Blundell e Bond (1998). Entre as variáveis de controle, estão características específicas das instituições e do setor financeiro e condições macroeconômicas do país. Essa abordagem de modelar rentabilidade bancária via estimação de painel dinâmico é uma novidade para literatura de finanças bancárias no Brasil.

Os resultados da especificação dinâmica sugerem moderada persistência dos níveis de rentabilidade das instituições bancárias no Brasil, mas com alta velocidade de ajustamento e existência de uma estrutura de mercado competitivo no setor. Isso ocorre por causa da disputa para ampliar a participação individual no mercado, que é reconhecidamente dominado por poucas instituições.

Dentre os perfis de instituições apontados como mais rentáveis, pode-se destacar os bancos privados e nacionais. Ainda nesse aspecto, os bancos organizados em conglomerado de instituições, bem como aqueles com ações negociadas na bolsa de valores mostraram-se menos rentáveis.

As estratégias de fusões e/ou aquisições desfavorecem a rentabilidade das instituições financeiras no período do negócio. Há uma defasagem de aproximadamente um ano para que fusões e/ou aquisições influenciem positivamente a rentabilidade do adquirente. Isso se explica pelos ajustes requeridos no período após o negócio.

Com relação ao tamanho das instituições financeiras, os resultados indicaram a existência de ganhos de escala ou escopo por parte dos bancos no país. Além disso, maiores participações de capitais próprios e de aplicações em títulos resultam, em geral, em maiores níveis de rentabilidade.

Outro resultado interessante diz respeito ao efeito da concentração bancária, medida pelo $\mathrm{IHH}$, sobre a rentabilidade do setor. A estimação sugeriu que a maior concentração do setor pode ser consequência do maior grau de competitividade por aumento na participação de mercado, que tem provocado alianças, fusões e aquisições de instituições concorrentes. Tal resultado vai, inclusive, ao encontro daquele obtido para a relação entre fusões e/ou aquisições e rentabilidade. $\mathrm{O}$ aumento das fusões e/ou aquisições provoca uma elevação da concentração no setor, o que, por sua vez, apresentou um impacto negativo sobre a rentabilidade. 
Assim, ao incorrer em disputas por maior participação no mercado, as instituições financeiras acabam por incorrer em perdas de rentabilidade.

Por fim, o ambiente macroeconômico representado por taxa de juros, taxa de inflação e crescimento econômico impacta positivamente na rentabilidade do setor financeiro. Cabe destacar o efeito positivo da taxa de inflação, revelando que as instituições vêm antecipando corretamente os efeitos inflacionários na precificação. Já a relação com a política monetária revela que instituições com maior participação de aplicações em tesouraria obtêm maiores rentabilidades por causa da elevada taxa de juro e reduzido nível de risco dos títulos públicos brasileiros.

\section{Referências}

ALMEIDA JÚNIOR, E.S. Sistema tributário, governança corporativa e abertura de capital: Brasil versus Estados Unidos. 2007. 94 f. Dissertação (Mestrado em Economia) - Instituto de Economia, Universidade Federal de Uberlândia, Uberlândia, 2007.

ARAUJO, C. A. G. et al. Estratégia de fusão e aquisição bancária no Brasil: evidências empíricas sobre retornos. In: CONGRESSO USP DE CONTROLADORIA E CONTABILIDADE, 5., 2005, São Paulo. Anais... São Paulo: USP, 2005.

ARELLANO, M.; BOND, S. Some tests of specification for panel data: Monte Carlo evindence and an application to employment equations. Review of Economic Studies, Bristol, v. 58, n. 2, p. 277-297, Apr. 1991.

ARELLANO, M.; BOVER, O. Another look at the instrumental variable estimation of error-components models. Journal of Econometrics, Amsterdam, v. 68, n. 1, p. 29-51, Jul. 1995.

ATHANASOGLOU, P. P.; DELIS, M. D.; STAIKOURAS, C. K. Determinants of Bank Profitability in the South Eastern European Region. Bank of Greece Working Paper, Athens, n. 47, p. 1-36, Sep. 2006.

ATHANASOGLOU, P. P.; BRISSIMIS, S. N.; DELIS, M. D. Bank-specific, industry-specific and macroeconomic determinants of bank profitability. Journal of International Financial Markets, Institutions and Money, Amsterdam, v. 18, n. 2, p. 121-136, Apr. 2008.

BERGER, A.N. et al. Why are bank profits so persistent? The roles of product market competition, informational opacity, and regional / macroeconomic shocks. Journal of Banking and Finance, Amsterdam, v. 24, n. 7, p. 1203-1235, Jul. 2000.

BLUNDELL, R.; BOND, S. R. Initial conditions and moment restriction in dynamic panel data models. Journal of Econometrics, Amsterdam, v. 87, n. 1, p. 115-143, Nov. 1998

BRANDÃO, M. M. et al. Marketing e performance no setor bancário brasileiro. In: CONGRESSO USP DE CONTROLADORIA E CONTABILIDADE, 5., 2005, São Paulo. Anais... São Paulo: USP, 2005.

CARVALHO, F. J. C. Estrutura e padrões de competição no sistema bancário brasileiro: uma hipótese para investigação e alguma evidência empírica. In: PAULA, L.F.; OREIRO, J.L. Sistema financeiro: uma análise do setor bancário brasileiro. Rio de Janeiro: Elsevier, 2007. p. 103-123. 
FARIA, J.A.; PAULA, L.F.; MARINHO, A. Eficiência no setor bancário brasileiro: a experiência recente das fusões e aquisições. In: PAULA, L. F.; OREIRO, J. L. Sistema financeiro: uma análise do setor bancário brasileiro. Rio de Janeiro: Elsevier, 2007. p. 125-154.

FLAMINI, V.; MCDONALD, C.; SCHUMACHER, L. The Determinants of Commercial Bank Profitability in Sub-Saharan Africa. International Monetary Fund Working Paper, Washington, n. 09/15, Jan. 2009.

GARCÍA-HERRERO, A.; GAVILÁ, S.; SANTABÁRBARA, D. What explains the low profitability of Chinese Banks. Journal of Banking and Finance, Amsterdam, v. 33, n. 11, p. 2080-2092, Nov. 2009.

GARZA-GARCIA, J. G. Determinants of Bank Performance in Mexico: Efficiency or Market Power. Centre for Global Finance Working Paper, Bristol, v. 11, n. 3, May 2011.

GODDARD, J.; MOLYNEUX, P.; WILSON, J. O. S. Dynamics of Growth and Profitability in Banking. Journal of Money, Credit and Banking, Columbus, v. 36, n. 6, p. 1069-1090, Dec. 2004.

GUIMARÃES, P. How does foreign entry affect the domestic banking marketing? The Brazilian case. Latin American Business Review, Binghamton, v. 3, n. 4, p. 121-140, Sep. 2002.

HANSEN, L. Large sample properties of generalized method of moments estimators. Econometrica, Chicago, v. 50, n. 4, p. 1029-1054, Jul. 1982.

LEAL, R.M. Estrutura e determinantes do spread bancário no Brasil após 1994: uma análise da literatura empírica. In: PAULA, L. F.; OREIRO, J. L. Sistema financeiro: uma análise do setor bancário brasileiro. Rio de Janeiro: Elsevier, 2007. p. 221-251.

LUCINDA, C. Competition in the Brazilian loan market: an empirical analysis. Estudos Econômicos, São Paulo, v. 40, n. 4, p. 831-858, out./dez. 2010.

MAFFILI, D. W.; BRESSAN, A. A.; SOUZA, A. A. Estudo da rentabilidade dos bancos brasileiros de varejo no período de 1999 a 2005. Contabilidade Vista 8 Revista, Belo Horizonte, v. 18, n. 2, p. 117-138, abr./jun. 2007.

MATOS, J.A. Theoretical foundations of corporate finance. New Jersey: Princenton University Press, 2001.

MODENESI, A. M. Teoria da intermediação financeira, o modelo ECD e sua aplicação aos bancos: uma resenha. In: PAULA, L. F.; OREIRO, J. L. Sistema financeiro: uma análise do setor bancário brasileiro. Rio de Janeiro: Elsevier, 2007. p. 61-99.

MOLINA, W. S. L. A reestruturação do Sistema Bancário Brasileiro nos anos 90: menos concorrência e mais competitividade ? Revista Intellectus, Sumaré, v. 3, n. 3, p. 76-96, ago./ dez.2004.

NAKANE, M. I. A Test of Competition in Brazilian Bank. Estudos Econômicos, São Paulo, v. 32, n. 2, p. 203-224, abr./jun. 2002.

Concorrência e spread bancário: uma revisão da evidência para o Brasil. In: BANCO CENTRAL DO BRASIL. Economia bancária e crédito: avaliação de 4 anos do projeto Juros e Spread Bancário. Brasília: BACEN, 2003.

NAVARRO, P. S.; PROCIANOY, J. L. A reação dos acionistas à institucionalização do banco múltiplo. Revista de Administração, São Paulo, v. 32, n. 1, p. 68-79, jan./mar. 1997. 
NOVAES, A. Intermediação financeira, bancos estatais e o mercado de capitais: a experiência internacional. In: PINHEIRO, A. C.; OLIVEIRA FILHO, L. C. Mercado de capitais e bancos públicos: análise e experiências comparadas. Rio de Janeiro: ContraCapa, 2007. p. 35-132.

OLIVEIRA, R. F.; SCHIOZER, R. F.; SAITO, R. A recente onda de abertura de capital de bancos no Brasil. In: ENCONTRO BRASILEIRO DE FINANÇAS, 9., 2009, São Leopoldo. Anais ... São Leopoldo: Unisinos, 2009.

PARKIN, M. Microeconomics. 3th ed. Massachusetts: Addison: Wesley, 1995.

PAULA, L. F.; PIRES, M. C. C. Determinantes macroeconômicos do spread bancário: uma análise preliminar para economias emergentes. In: PAULA, L. F.; OREIRO, J. L. Sistema financeiro: uma análise do setor bancário brasileiro. Rio de Janeiro: Elsevier, 2007. p. 171-189.

PERRY, P. D. Do Banks Gain or Lose From Inflation? Journal of Retail Banking, v. 14, n. 2, p. 25-40, 1992.

PINHEIRO, A. C. Bancos públicos no Brasil: para onde ir ? In: PINHEIRO, A. C.; OLIVEIRA FILHO, L. C. Mercado de capitais e bancos públicos: análise e experiências comparadas. Rio de Janeiro: ContraCapa, 2007. p. 159-263.

ROCHA, F. A. S. Evolução da concentração bancária no Brasil (1994-2000). Notas Técnicas do Bacen, Brasília, n. 11, p. 1-41, nov. 2001.

ROSS, S. A.; WESTERFIELD, R. W.; JAFFE, J. F. Administração financeira: corporate finance. São Paulo: Atlas, 1995.

SILVA, G. J. C.; OREIRO, J. L.C. Taxa de Juros Convencional e Rentismo em um Modelo Pós-Keynesiano de Firma Bancária. In: PAULA, L. F.; OREIRO, J. L. Sistema financeiro: uma análise do setor bancário brasileiro. Rio de Janeiro: Elsevier, 2007. p. 23-44.

SILVA, G. J. C.; OREIRO, J. L. C.; PAULA, L. F. Spread bancário no Brasil: uma avaliação empírica recente. In: PAULA, L. F.; OREIRO, J. L. Sistema financeiro: uma análise do setor bancário brasileiro. Rio de Janeiro: Elsevier, 2007. p. 191-220.

SOBREIRA, R. Racionamento de crédito e comportamento da firma bancária: uma abordagem pós-keynesiana. In: PAULA, L. F.; OREIRO, J. L. Sistema financeiro: uma análise do setor bancário brasileiro. Rio de Janeiro: Elsevier, 2007. p. 45-60.

SUFIAN, F.; HABIBULLAH, M. S. Bank specific and macroeconomic determinants of bank profitability: Empirical evidence from the China banking sector. Frontiers of Economics in China, Heidelberg, v. 4, n. 2, p. 274-291, Jun. 2009.

TREGENNA, F. The fat years: the structure and profitability of the US banking sector in the pre-crisis period. Cambridge Journal of Economics, London, v. 33, n. 4, p. 609-632, Jul. 2009. 
Anexo A - Estimações com Dummy de Interação pxa, fa em até t-4 e CR10

\begin{tabular}{|c|c|c|c|c|c|c|}
\hline & Dummy d & eração $p x a$ & Dummy fa & $\begin{array}{l}\text { lasada em } \\
4\end{array}$ & CR1O sub & lindo $I H H$ \\
\hline & ROE & ROA & ROE & ROA & ROE & ROA \\
\hline constante & $\begin{array}{c}-0,414^{* *} \\
(0,169)\end{array}$ & $\begin{array}{l}-0,010 \\
(0,029)\end{array}$ & $\begin{array}{c}0,042 \\
(0,170)\end{array}$ & $\begin{array}{l}-0,006 \\
(0,025)\end{array}$ & $\begin{array}{l}-0,213 \\
(0,192)\end{array}$ & $\begin{array}{c}0,030 \\
(0,030)\end{array}$ \\
\hline $\begin{array}{l}\text { endógena } \\
(t-1)\end{array}$ & $\begin{array}{c}0,101^{* * *} \\
(0,005)\end{array}$ & $\begin{array}{c}0,148^{* * *} \\
(0,005)\end{array}$ & $\begin{array}{c}0,108^{* * *} \\
(0,005)\end{array}$ & $\begin{array}{c}0,155^{* * *} \\
(0,005)\end{array}$ & $\begin{array}{c}0,098^{* * *} \\
(0,003)\end{array}$ & $\begin{array}{c}0,142 * * * \\
(0,004)\end{array}$ \\
\hline $\begin{array}{l}a b \\
\text { (dummy) }\end{array}$ & $\begin{array}{c}0,036^{* * *} \\
(0,014)\end{array}$ & $\begin{array}{l}0,008^{*} \\
(0,005)\end{array}$ & $\begin{array}{c}-0,042 * * * \\
(0,005)\end{array}$ & $\begin{array}{c}-0,005 * * * \\
(0,001)\end{array}$ & $\begin{array}{c}-0,044^{* * *} \\
(0,004)\end{array}$ & $\begin{array}{c}-0,004^{* * *} \\
(0,001)\end{array}$ \\
\hline $\begin{array}{l}\text { pxa } \\
\text { (dummy) }\end{array}$ & $\begin{array}{c}-0,087^{* * *} \\
(0,019)\end{array}$ & $\begin{array}{c}-0,013^{* * *} \\
(0,005)\end{array}$ & & & & \\
\hline $\begin{array}{l}\text { fa } \\
\text { (dummy) }\end{array}$ & $\begin{array}{l}-0,003^{*} \\
(0,001)\end{array}$ & $\begin{array}{c}0,000 \\
(0,000)\end{array}$ & $\begin{array}{c}-0,004^{* * *} \\
(0,001)\end{array}$ & $\begin{array}{c}-0,001^{* *} \\
(0,000)\end{array}$ & $\begin{array}{l}-0,002 \\
(0,002)\end{array}$ & $\begin{array}{l}-0,001^{*} \\
(0,000)\end{array}$ \\
\hline $\begin{array}{l}f a_{\mathrm{t}-1} \\
\text { (dummy) }\end{array}$ & & & $\begin{array}{c}0,002 \\
(0,002)\end{array}$ & $\begin{array}{c}0,000 \\
(0,000)\end{array}$ & & \\
\hline $\begin{array}{l}f a_{\mathrm{t}-2} \\
\text { (dummy) }\end{array}$ & & & $\begin{array}{l}-0,003^{*} \\
(0,002)\end{array}$ & $\begin{array}{l}-0,001^{* * *} \\
(0,000)\end{array}$ & & \\
\hline $\begin{array}{l}f a_{t-3} \\
\text { (dummy) }\end{array}$ & & & $\begin{array}{c}0,009 \\
(0,007)\end{array}$ & $\begin{array}{c}0,001 \\
(0,001)\end{array}$ & & \\
\hline $\begin{array}{l}f a_{\mathrm{t}-4} \\
\text { (dummy) }\end{array}$ & & & $\begin{array}{l}0,008^{* *} \\
(0,003)\end{array}$ & $\begin{array}{c}0,001 \\
(0,001)\end{array}$ & & \\
\hline $\begin{array}{l}\text { prs } \\
\text { (dummy) }\end{array}$ & $\begin{array}{c}0,158^{* * *} \\
(0,016)\end{array}$ & $\begin{array}{c}0,030^{* * *} \\
(0,004)\end{array}$ & $\begin{array}{c}0,088^{* * *} \\
(0,014)\end{array}$ & $\begin{array}{c}0,016^{* * *} \\
(0,002)\end{array}$ & $\begin{array}{c}0,074^{* * *} \\
(0,012)\end{array}$ & $\begin{array}{c}0,018^{* * *} \\
(0,002)\end{array}$ \\
\hline $\begin{array}{l}\text { prt } \\
\text { (dummy) }\end{array}$ & $\begin{array}{c}-0,016^{* * *} \\
(0,002)\end{array}$ & $\begin{array}{c}-0,007^{* * *} \\
(0,001)\end{array}$ & $\begin{array}{c}-0,009^{* * *} \\
(0,004)\end{array}$ & $\begin{array}{c}-0,008^{* * *} \\
(0,001)\end{array}$ & $\begin{array}{c}-0,014^{* * *} \\
(0,002)\end{array}$ & $\begin{array}{c}-0,006^{* * *} \\
(0,001)\end{array}$ \\
\hline $\begin{array}{l}\text { ctl } \\
\text { (dummy) }\end{array}$ & $\begin{array}{c}0,087^{* * *} \\
(0,006)\end{array}$ & $\begin{array}{c}0,004^{* * *} \\
(0,001)\end{array}$ & $\begin{array}{c}0,079 * * * \\
(0,009)\end{array}$ & $\begin{array}{c}0,004^{* * *} \\
(0,001)\end{array}$ & $\begin{array}{c}0,091^{* * *} \\
(0,007)\end{array}$ & $\begin{array}{c}0,005^{* * *} \\
(0,001)\end{array}$ \\
\hline atc & $\begin{array}{c}0,151^{* * *} \\
(0,055)\end{array}$ & $\begin{array}{c}0,009 \\
(0,009)\end{array}$ & $\begin{array}{c}0,016 \\
(0,052)\end{array}$ & $\begin{array}{l}0,014^{*} \\
(0,008)\end{array}$ & $\begin{array}{l}0,118^{* *} \\
(0,061)\end{array}$ & $\begin{array}{c}0,002 \\
(0,009)\end{array}$ \\
\hline atc 2 & $\begin{array}{l}-0,007^{*} \\
(0,004)\end{array}$ & $\begin{array}{c}0,000 \\
(0,001)\end{array}$ & $\begin{array}{c}0,003 \\
(0,004)\end{array}$ & $\begin{array}{l}-0,001 \\
(0,001)\end{array}$ & $\begin{array}{l}-0,004 \\
(0,005)\end{array}$ & $\begin{array}{c}0,000 \\
(0,001)\end{array}$ \\
\hline pma & $\begin{array}{c}0,284 \\
(0,625)\end{array}$ & $\begin{array}{l}-0,151 \\
(0,205)\end{array}$ & $\begin{array}{c}-2,247^{* * *} \\
(0,573)\end{array}$ & $\begin{array}{c}-0,366^{* *} \\
(0,183)\end{array}$ & $\begin{array}{l}-1,291^{*} \\
(0,684)\end{array}$ & $\begin{array}{l}-0,333^{*} \\
(0,177)\end{array}$ \\
\hline pcld & $\begin{array}{c}-0,244^{* * *} \\
(0,015)\end{array}$ & $\begin{array}{c}-0,076^{* * *} \\
(0,002)\end{array}$ & $\begin{array}{c}-0,220^{* * *} \\
(0,019)\end{array}$ & $\begin{array}{c}-0,078^{* * *} \\
(0,003)\end{array}$ & $\begin{array}{c}-0,232^{* * *} \\
(0,009)\end{array}$ & $\begin{array}{c}-0,076^{* * *} \\
(0,002)\end{array}$ \\
\hline$t x c r$ & $\begin{array}{c}0,027^{* * *} \\
(0,003)\end{array}$ & $\begin{array}{c}0,001^{* * *} \\
(0,000)\end{array}$ & $\begin{array}{c}0,027^{* * *} \\
(0,003)\end{array}$ & $\begin{array}{c}0,001^{* * *} \\
(0,000)\end{array}$ & $\begin{array}{c}0,032^{* * *} \\
(0,002)\end{array}$ & $\begin{array}{c}0,001^{* * *} \\
(0,000)\end{array}$ \\
\hline$c t x p$ & $\begin{array}{c}-0,318^{* * *} \\
(0,012)\end{array}$ & $\begin{array}{c}-0,036^{* * *} \\
(0,002)\end{array}$ & $\begin{array}{c}-0,314^{* * *} \\
(0,018)\end{array}$ & $\begin{array}{c}-0,040^{* * *} \\
(0,002)\end{array}$ & $\begin{array}{c}-0,326^{* * *} \\
(0,011)\end{array}$ & $\begin{array}{c}-0,039^{* * *} \\
(0,003)\end{array}$ \\
\hline$d s a t$ & $\begin{array}{c}-3,008^{* * *} \\
(0,171)\end{array}$ & $\begin{array}{c}-0,286^{* * *} \\
(0,016)\end{array}$ & $\begin{array}{c}-2,362^{* * *} \\
(0,257)\end{array}$ & $\begin{array}{c}-0,276^{* * *} \\
(0,022)\end{array}$ & $\begin{array}{c}-2,687^{* * *} \\
(0,199)\end{array}$ & $\begin{array}{c}-0,289^{* * * *} \\
(0,018)\end{array}$ \\
\hline tsa & $\begin{array}{c}5,253^{* * *} \\
(0,650)\end{array}$ & $\begin{array}{c}0,418^{* * *} \\
(0,111)\end{array}$ & $\begin{array}{c}3,274^{* * *} \\
(1,223)\end{array}$ & $\begin{array}{c}0,526^{* * *} \\
(0,037)\end{array}$ & $\begin{array}{c}4,681^{* * *} \\
(0,768)\end{array}$ & $\begin{array}{c}0,410^{* * *} \\
(0,112)\end{array}$ \\
\hline $\inf$ & $\begin{array}{c}0,749^{* * * *} \\
(0,179)\end{array}$ & $\begin{array}{c}0,194^{* * *} \\
(0,011)\end{array}$ & $\begin{array}{c}0,454^{* *} \\
(0,225)\end{array}$ & $\begin{array}{c}0,200^{* * *} \\
(0,011)\end{array}$ & $\begin{array}{l}0,382^{* *} \\
(0,187)\end{array}$ & $\begin{array}{c}0,210^{* * * *} \\
(0,012)\end{array}$ \\
\hline
\end{tabular}


conclusão...

\begin{tabular}{|c|c|c|c|c|c|c|}
\hline & \multicolumn{6}{|c|}{ Dummy fa defasada em } \\
\hline & ROE & ROA & ROE & ROA & ROE & ROA \\
\hline sel & $\begin{array}{c}0,610 * * * \\
(0,167)\end{array}$ & $\begin{array}{c}0,102 * * * \\
(0,006)\end{array}$ & $\begin{array}{l}0,352 * * \\
(0,161)\end{array}$ & $\begin{array}{c}0,095 * * * \\
(0,011)\end{array}$ & $\begin{array}{c}0,316 \\
(0,276)\end{array}$ & $\begin{array}{c}0,084^{* * *} \\
(0,008)\end{array}$ \\
\hline prod & $\begin{array}{c}0,116 * * * \\
(0,048)\end{array}$ & $\begin{array}{c}0,048 * * * \\
(0,006)\end{array}$ & $\begin{array}{l}0,113 * * \\
(0,058)\end{array}$ & $\begin{array}{c}0,031 * * * \\
(0,012)\end{array}$ & $\begin{array}{l}0,133^{*} \\
(0,077)\end{array}$ & $\begin{array}{c}0,037 * * * \\
(0,005)\end{array}$ \\
\hline comp & $\begin{array}{c}-0,035 * * * \\
(0,012)\end{array}$ & $\begin{array}{c}-0,005 * * * \\
(0,001)\end{array}$ & $\begin{array}{l}-0,014 \\
(0,014)\end{array}$ & $\begin{array}{c}-0,005 * * * \\
(0,001)\end{array}$ & $\begin{array}{l}-0,012 \\
(0,019)\end{array}$ & $\begin{array}{c}-0,003 * * * \\
(0,001)\end{array}$ \\
\hline ihh & $\begin{array}{c}0,130 \\
(0,179)\end{array}$ & $\begin{array}{c}-0,123 * * * \\
(0,014)\end{array}$ & $\begin{array}{c}0,204 \\
(0,231)\end{array}$ & $\begin{array}{c}-0,128 * * * \\
(0,015)\end{array}$ & & \\
\hline $\operatorname{cr} 10$ & & & & & $\begin{array}{l}-0,034 \\
(0,036)\end{array}$ & $\begin{array}{c}-0,024 * * * \\
(0,002)\end{array}$ \\
\hline $\begin{array}{l}\text { Wald-Test } \\
x^{2}\end{array}$ & $\begin{array}{c}(20)=68.109 \\
p-v a l=0,00\end{array}$ & $\begin{array}{c}(20)=325.189 \\
p-v a l=0,00\end{array}$ & $\begin{array}{c}(23)=66.560 \\
p-v a l=0,00\end{array}$ & $\begin{array}{c}(23)=137.410 \\
p-v a l=0,00\end{array}$ & $\begin{array}{c}(19)=37.532 \\
p-v a l=0,00\end{array}$ & $\begin{array}{c}(19)=16.716 \\
p-v a l=0,00\end{array}$ \\
\hline $\mathrm{AR}(1) \mathrm{z}$ & $\begin{array}{c}-3,71 \\
p-v a l=0,00\end{array}$ & $\begin{array}{c}-3,22 \\
p-v a l=0,00\end{array}$ & $\begin{array}{c}-3,67 \\
p-v a l=0,00\end{array}$ & $\begin{array}{c}-3,21 \\
p-v a l=0,00\end{array}$ & $\begin{array}{c}-3,70 \\
p-v a l=0,00\end{array}$ & $\begin{array}{c}-3,23 \\
p-v a l=0,00\end{array}$ \\
\hline $\mathrm{AR}(2) \mathrm{z}$ & $\begin{array}{c}0,40 \\
p-v a l=0,68\end{array}$ & $\begin{array}{c}0,07 \\
p-v a l=0,94\end{array}$ & $\begin{array}{c}0,65 \\
p-v a l=0,51\end{array}$ & $\begin{array}{c}0,10 \\
p-v a l=0,91\end{array}$ & $\begin{array}{c}0,37 \\
p-v a l=0,70\end{array}$ & $\begin{array}{c}0,05 \\
p-v a l=0,95\end{array}$ \\
\hline Sargan $x^{2}$ & $\begin{array}{c}(92)=55,300 \\
p-v a l=0,99\end{array}$ & $\begin{array}{c}(92)=55,389 \\
p-v a l=0,99\end{array}$ & $\begin{array}{c}(85)=47,128 \\
p-v a l=0,99\end{array}$ & $\begin{array}{c}(85)=54,192 \\
p-v a l=0,99\end{array}$ & $\begin{array}{c}(92)=53,606 \\
p-v a l=0,99\end{array}$ & $\begin{array}{c}(92)=54,456 \\
p-v a l=0,99\end{array}$ \\
\hline
\end{tabular}

Fonte: Elaboração própria.

Nota: $* *, * * e^{*}$ denotam significância estatística dos coeficientes a 1\%, 5\% e $10 \%$, respectivamente.

Recebido em: 25/09/2011.

Aceito em: 09/11/2012. 